\title{
LA INTERACTIVIDAD
}

A TRAVÉS DEL

CALEIDOSCOPIO DE LA

COMUNICACIÓN

\section{Presentación}

\section{Coordinador del número: Juan Salvador Victoria Mas}

\section{Profesor Titular}

Departamento de Comunicación Audiovisual y Publicidad. Facultad de Ciencias de la Comunicación. Universidad de Málaga. Campus de Teatinos s/n. 29071 Málaga (España) Email: jsvictoria@uma.es

\section{Datos del número \\ URL: www.icono14.net \\ Fecha de publicación: 1/01/2010 \\ Director de la revista: Francisco García García (Catedrático de Comunicación Audiovisual y Publicidad de la UCM) Coordinador del número: Juan Salvador Victoria Mas (Profesor titular de Comunicación Audiovisual y Publicidad)}

\section{Introducción}

El presente monográfico sobre Interactividad forma parte del proyecto de investigación CSO2009-11203 financiado en la convocatoria del Ministerio de Ciencia e Innovación dentro del Programa Nacional de Proyectos de Investigación Fundamental, en el marco del VI Plan Nacional de Investigación Científica, Desarrollo e Innovación Tecnológica 2008-2011 (IP Isidoro
Arroyo Almaraz), de título: “DESARROLLO DE UN MODELO DE EFICACIA DE LA COMUNICACION PERSUASIVA DEL TERCER SECTOR EN LAS REDES SOCIALES." Dicho proyecto de investigación está siendo llevado a cabo por la Universidad Rey Juan Carlos de Madrid y la Universidad de Málaga. 


\section{Presentación}

Pocas realidades hay en la actualidad -y así se afirma frecuentemente- que no sean poliédricas o, desde el lado del observador, que no precisen de un caleidoscopio para ser abarcadas holísticamente. Pero este instrumento en nuestro caso no hace otra cosa que complicar la tarea, ya que multiplica simétricamente las imágenes de una realidad - en el caso de la Comunicación quizá más que en ningún otro- ya de por sí caracterizada por su inabarcabilidad, por sus muchas (poli) caras (edro). Es decir, una multiplicación exponencial de una complejidad ya intrínseca.

Sin embargo, no hay otra forma que la de echar mano del caleidoscopio para analizar el concepto central del "sector" más importante de nuestra sociedad Transmoderna (Rodríguez Magda 2004): el concepto de Interactividad en el campo de la Comunicación.

Una afirmación como la anterior resulta reconocible como premisa y creemos que no requiere más demostración para la generalidad de la comunidad académica y profesional en el campo de la Comunicación. En cambio, el contexto en el que deliberadamente la circunscribimos -la Transmodernidad- quizá sí requiera un breve desarrollo.

Diversos autores y tesis, como el "capitalismo tardío" de Fredric Jameson (1991) o "la modernidad líquida" de Bauman (2006), han aportado argumentos a la tesis según la cual habríamos superado la Posmodernidad. Según Rodríguez Magda, en cualquier caso, debe realizarse una ruptura con la Posmodernidad para percibir realmente el cambio de paradigma y disponer de las herramientas conceptuales necesarias para entender nuestra época. Y es que realmente resulta caduca la afirmación según la cual son imposibles los "grandes relatos" (Lyotard, 1987). Existe al menos un gran relato y éste es el de la Globalización, debido fundamentalmente al efecto inesperado de las tecnologías de la Información y de la Comunicación.

Todo está interconectado configurando un magma fluctuante, difuso, totalizador. Líquido en definitiva (el agua se constituye en la más conveniente de las metáforas). Por tanto, más que el prefijo "post” sería “trans” el más apropiado para caracterizar la situación, dado que connota la forma actual de transcender los límites de la Modernidad, nos habla de un mundo en constante transformación, basado no sólo en los fenómenos transnacionales, sino en el primado de la transmisibilidad de información en tiempo real, en el que la creación remite a una transtextualidad.

Pues bien, es este último aspecto tan esencial a nuestros tiempos que justificaría el cambio de denominación de todo el movimiento cultural e intelectual contemporáneo. Y de este contexto a la definición de 
partida del concepto genérico de Interactividad no hay más que un paso; tal y como lo han expuesto Mora, para quien la "interfaz hipermedia" (entendida ésta como la superación del hipertexto que sólo incluye texto o imagen fija) sería el paradigma de la comunicación interactiva (2009), u Ori- huela (a quien entrevistamos a continuación): "Estamos experimentando actualmente la interactividad como un discurso fluido ("líquido" en términos de Bauman), fragmentado y distribuido, característico de las redes sociales y muy especialmente del microblogging”.

\section{Hipótesis de partida}

En este sentido, cabría hablar del hipertexto como el rasgo más definitorio de la sociedad interactiva en la medida que concreta esa liquidez que atribuimos esencialmente a las comunicaciones digitales de nuestros días. Esta hipótesis estaría implícita ya desde que Negroponte (1995) definiese la digitalización como el paso de átomos (materia) a bits (información) que facilita la transmisión y aumenta las posibilidades de combinación de elementos dando lugar a contenidos multimedia.

Se suele cifrar el germen del sistema hipertextual en el dispositivo MEMEX que Vannebar Bush describe en 1945. Pero no sería hasta Landow (1991) que se definiese éste tal y como lo conocemos actualmente unido sustancialmente a la tecnología digital: "trascendencia de la linealidad, límites y calidad fija de la tradicional forma de escritura textual”.

El hipertexto vendría a ser el modelo de comunicación más cercano a la estructura humana, basada en la continua relación entre ideas e información, y no sólo efectivamente- la posibilidad de enlazar un texto con otro o de activar un enlace para extraer su contenido (García 2006). El hipertexto permite la superación del discurso secuencial de los mass media, de su espacio y su tiempo, en pro de la ruta más adecuada escogida por el receptor para el cumplimiento de sus expectativas. 


\section{Estructura y contenidos del monográfico}

Como parte de la Introducción, incluimos también en nuestro monográfico un artículo de Martínez y Cabezuelo acerca del contexto y el concepto de la Interactividad, incidiendo en la problemática de la entropía, y otro de Godzic - un significativo compatriota de Bauman- que nos propone el paradigma del medio televisivo convencional, a través del ejemplo de la televisión polaca, como espejo donde se ha reflejado privilegiadamente ese movimiento irrefrenable de interactividad.

A partir de aquí, el planteamiento investigador que presentamos parte de las perspectivas que conforman nuestro peculiar caleidoscopio: los ámbitos a través de los cuales se ha estudiado tradicionalmente la Comunicación: Publicidad, Comunicación Audiovisual, Periodismo y Relaciones Públicas. A estas disciplinas añadimos algunos de los temas que más recurrentemente se asocian en la actualidad a nuestro objeto de estudio: Movilidad, Educación, Accesibilidad y Lenguaje.

En cuanto a la Publicidad -espacio pionero de Interactividad según Orihuela-, Méndiz y Loayza coinciden en la relevancia de los juegos en las propuestas publicitarias; De Salas, en los formatos de las redes sociales y en su búsqueda de resolución del conflicto de la intrusividad.
En cuanto a la Comunicación Audiovisual ámbito al que pertenecería ese espejo privilegiado de Godzic-, todos los autores que participan en este apartado coinciden en resaltar un aspecto central de la Interactividad sobre todos los demás: la creación colectiva y la colaboración.

Desde el ámbito del Periodismo, Cabrera y García nos hablan de los aspectos de la convergencia y de la inmediatez, respectivamente, a la que daría lugar la Interactividad.

Las Relaciones Públicas se han ocupado, según Castillo y Becerra, especialmente de la globalización de ciertas "culturas" anglosajonas como las implícitas en lobbies, think tanks y en las comunicaciones corporativas, culturas que nos hablan de otras formas y estilos de hacer comunicación más propositivas y menos impositivas, más su-gerentes y menos insistentes.

La Movilidad es uno de los panoramas de futuro (con todas sus carencias en la actualidad) de extensión natural para la Interactividad, según Ruiz del Olmo y Gómez. El receptor es dinámico (Martínez). El lenguaje, Metalenguaje en realidad (Berlanga). El aprendizaje, colaborativo (Díaz). Y finalmente, un mensaje esperanzador: la Interactividad tiene un enorme potencial y gran sensibilidad para la accesibilidad (Rodríguez y García). 


\section{A la estela del Manifiesto Cluetrain}

Todo esto sería coherente, podríamos afirmar, con la declaración simplista de la publicidad actual a través de uno de sus acrónimos de letra reincidente: las tres $\mathrm{C}^{\prime} \mathrm{s}$ que suponen los pilares de la Red 2.0: conversar, colaborar y contribuir.

En definitiva, aportaciones muy coincidentes con los postulados de David Weinberger, coautor de El Manifiesto Cluetrain, que varios de los autores de este mismo monográfico sintetizábamos hace algunos años (Victoria 2004):

1. CONVERSACIÓN: Los mercados son conversaciones.

2. POSIBLES DIÁLOGOS IMPOSIBLES: Los medios digitales hacen posibles diálogos que antes eran imposibles. Éstos tienen lugar entre seres humanos.

3. DiÁlogOS AUTÉNTICOS Y CERCANOS: Las conversaciones entre seres humanos suenan humanas y tratan acerca de las inquietudes humanas. La voz humana es abierta, natural y sincera.

4. HOMBRE Y SOCIEDAD: Estas conversaciones son más interesantes que la mayoría de la publicidad y, ciertamente, más cercanas a la vida real.

5. ESCUCHA: Como personas, pedimos frecuentemente que nos escuchen. Los comunicadores deben hacer esto sobre todo.

6. LOS CONTENIDOS SON DEL USUARIO Y PARA EL USUARIO: Las personas han descubierto que pueden obtener mucha mejor información y soporte entre sí mismos que de los vendedores. Saben más que las empresas acerca de sus propios productos.

7. SENTIDO DEL HUMOR: Las empresas deben comunicarse con sus mercados directamente. Deben bajar de su pedestal y hablarle a la gente con quien esperan establecer relaciones. Deben darse cuenta de que sus clientes se ríen frecuentemente de ellas.

8. REALISMO: Este nuevo paradigma nos parece mucho mejor. De hecho, somos nosotros quienes lo estamos creando. Estamos despertando y conectándonos. Estamos observando. Pero no estamos quietos.

9. COMUNICACIÓN: Lo importante es comunicarse, el resto es tecnología (Erikson) 


\section{Una reivindicación}

En otras palabras, se trata de una reivindicación antropológica, frente a los efectos perversos de la Interactividad, ya expuesta significativamente -y casi paradójicamenteen una de las revistas de Sociología más relevantes de la actualidad: Prisma Social (Victoria 2008). Propongo profundizar especialmente en la actualidad- en las aportaciones, diferenciadas de la Sociología y la Sicología, de etnógrafos y antropólogos como Honoré (2008) y su "movimiento slow”, Michael Wesch (2007), o Ellis (2002): "los hombres deberían ser le alfa y omega de las comunicaciones digitales”.

Si el marketing por ejemplo acude cada vez más recurrentemente a terminologías alejadas de ese "publico objetivo", target o -la peor de todas- "nichos", para poner de relieve, por contraste, la importancia de la personalización de los mensajes y de la comunicación relacional, por supuesto entre personas. Si la publicidad descubre en sus copies el talismán de la palabra persona y prefiere tatar al receptor de tú a tú, para lo cual hace uso de distintas terminologías: "one to one", one2one, 1to1, 1:1, o incluso 121, o abusar incluso de términos como fidelización o fidelizar, cualitativo frente a cuantitativo, diálogo y escucha, etc. Si esto es así, afirmamos, se da una dimensión antropológica que adolece claramente de profundización.

Cuando se habla de "one to one", por ejemplo, se destaca la individualización de los mensajes y la creciente importancia del receptor/consumidor y del conocimiento acerca de éste. En general, no se trata de llegar a muchos con parámetros cuantitativos sino de acercarse a cada persona. Y esta relación interpersonal auténtica descansa, cada vez más, sobre la empatía o conocimiento por connaturalidad, uno de los principales aspectos de la llamada inteligencia emocional (Goleman, 1997: 162183). Resulta significativo el título de un libro como El mercado son personas, de Joseph Chías (1990). O también algunos de los textos de Alfons Cornellá (2002): "Mercados y conversaciones, escuchar al cliente”. Pero quizá se carece de nociones realmente fundamentadas - y fundamentadoras- acerca de lo que se declara tantas veces de forma tan solemne.

Desde esta perspectiva, se han realizado las más interesantes aportaciones a nuestro objeto de estudio. Pero en todo caso, siempre necesitadas de desarrollo. Sirvan como muestra dos "botones" bien separados en el tiempo.

Hace más de tres décadas, el genial Gregory Bateson (1979) formulaba varias preguntas que podríamos recoger hoy más que nunca: "¿qué pauta conecta al cangrejo con la langosta?, ¿y a la orquídea con el girasol?, ¿y qué es lo que une todo aquello entre sí?, ¿y a todos ellos conmigo?, ¿y a usted conmigo?, ¿y a todos (nosotros y aquéllos) con el esquizofrénico que ence- 
rramos?" ¿Cuál es la pauta que conecta a todas las criaturas vivas entre sí? Es decir, ¿cuál es la relación entre esta comunicación líquida y la decepción (Lipovestky 2008)?

O Piscitelli (2009), cuando se pregunta qué tienen que ver los nativos digitales con las formas tecnológicas de vida. Qué tiene que ver la innovación con quienes dicen quererla pero en el fondo la detestan. Los adolescentes que viven inmersos en la tecnología con los adultos que la recelan y la desconocen. La dieta cognitiva de las últimas generaciones ha cambiado en forma tan abismal que la comunicación entre niños/jóvenes y adultos nos está llevando hacia una ruptura de consecuencias culturalmente catastrófi- cas. A menos que los adultos abandonemos nuestra soberbia y empecemos a hablar el lenguaje de los jóvenes. Y, correlativamente, que los niños/jóvenes abandonen el cascarón de su autismo filotecnológico y recuperen lo más valioso del canon occidental y oriental. Tal tarea consistente en el diseño de docentes y adultos 2.0 es un programa aún por formular. Nosotros deberíamos delimitar un territorio e invitar a poblarlo.

Bateson o Pisicitelli están rozando lo esencial. A veces las cuestiones complejas y poliédricas se basan en principios simples: los hombres, las personas y sus conversaciones (o falta de ellas).

\section{Referencias}

BATESON, G: Espíritu y naturaleza: una unidad necesaria (avances en teoría de sistemas, complejidad y ciencias humanas). Bantam Books, 1979.

BAUMAN, Z: Vida Líquida, Paidós Ibérica, Barcelona 2006.

CORNELLÁ: "Mercados y conversaciones, escuchar al cliente", 5 de mayo de 2000:

http://www.bitniks.es/bn/ARCHIVO/ECONO/ 33/01.shtml.

CHÍAS, J: El mercado son personas, McGraw Hill, Madrid 1990.

ELLIS, L: "Digital Humanism: The Outside of Cyberspace", ClickZ Today, 31 de julio de 2002: http://www.clikz.com

GARCÍA, F: "Contenidos educativos digitales: Construyendo la Sociedad del Conocimiento”, Red Digital 6, 2006.

GOLEMAN, D: Inteligencia emocional, Kairós, Barcelona 1997.
HONORÉ, C: Elogio de la lentitud, RBA, Barcelona 2008.

JAMESON, F: El posmodernismo o la lógica cultural del capitalismo avanzado, Paidós, Barcelona 1991.

LANDOW, G: Hypermedia and Literary Studies, Cambridge: MIT Press 1991.

LIPOVETSKY, G: La sociedad de la decepción, Anagrama, Barcelona 2008.

LYOTARD, JF: La condición postmoderna, Cátedra, Madrid 1987.

MORA, J: La interfaz hipermedia: el paradigma de la comunicación interactiva. Modelos para implementar la inmersión juvenil en multimedia interactivos culturales, Datautor, Madrid, 2009.

NEGROPONTE, N: El mundo digital, Ediciones B, Barcelona 1995 
PISCITELLI, A: Dieta Cognitiva Inteligencia Colectiva y Arquitecturas de la Participación, 2009: http: / /www. nativos-digitales.com.ar/

RODRÍGUEZ MAGDA, RM: Transmodernidad, Anthropos, Barcelona 2004.

VICTORIA, JS: “Ciudadanos, Públicos y Consumidores: Personas. Propuestas del Personalismo para el estudio de la Comunicación. El receptor como persona”, Prisma Social 1, diciembre de 2008: http://www.isdfundacion.es/ publicaciones/revista/

VICTORIA, JS: Manifiesto ComInteractiva. A propósito de Cluetrain, diálogos sobre le diálogo, en Congreso Internacional de Comunicación Interactiva, marzo de 2004: http: / / www.com interactiva.com/manifiesto09.htm

WESCH, M: Machine is us, Digital Etnography, Kansas State University 2007:

http: //mediatedcultures.net/ksudigg/?p=84

\section{Cita de este artículo}

Victoria Mas, J.S. (2009) La interactividad a través del caleidoscopio de la comunicación: Presentación. Revista Icono14 [en línea] 15 de Enero de 2010, № 15. pp. 0108. Recuperado (Fecha de acceso), de http://www.icono14.net 